\title{
Nursing management of subarachnoid haemorrhage: A reflective case study
}

Fiona Lange is a clinical nurse and postgraduate student in the master of advanced practice (acute care) programme, Griffith University, Queensland 4102, Australia

$\mathrm{n}$ most populations the incidence of subarachnoid haemorrhage is 6-7 per 100000 persons, although in

Finland and Japan the incidence is around 20 per 100000 (van Gijn et al, 2007). Forty per cent of patients with subarachnoid haemorrhage die, and $30 \%$ of survivors are left with significant neurological disability (Edlow, 2007).

In this reflective case study Gibbs's 'reflective cycle' (1988) is used in conjunction with the case study approach of Aitkin and Marshall (2007) to critically reflect on and analyse the care and management of an acutely ill neuroscience patient with subarachnoid haemorrhage (Figure 1). The value of reflection and the usefulness of Gibbs's cycle in reflective nursing practice will be considered. The patient's history, diagnostic findings and nursing management of postoperative coiling will be discussed with reference to specific nursing roles for the care of a patient with subarachnoid haemorrhage, such as the conduct of neurological observations using the Glasgow Coma Scale (GCS) (Table 1), blood pressure control, Cushing's triad, pupillary assessment, fluid management, vasospasm and

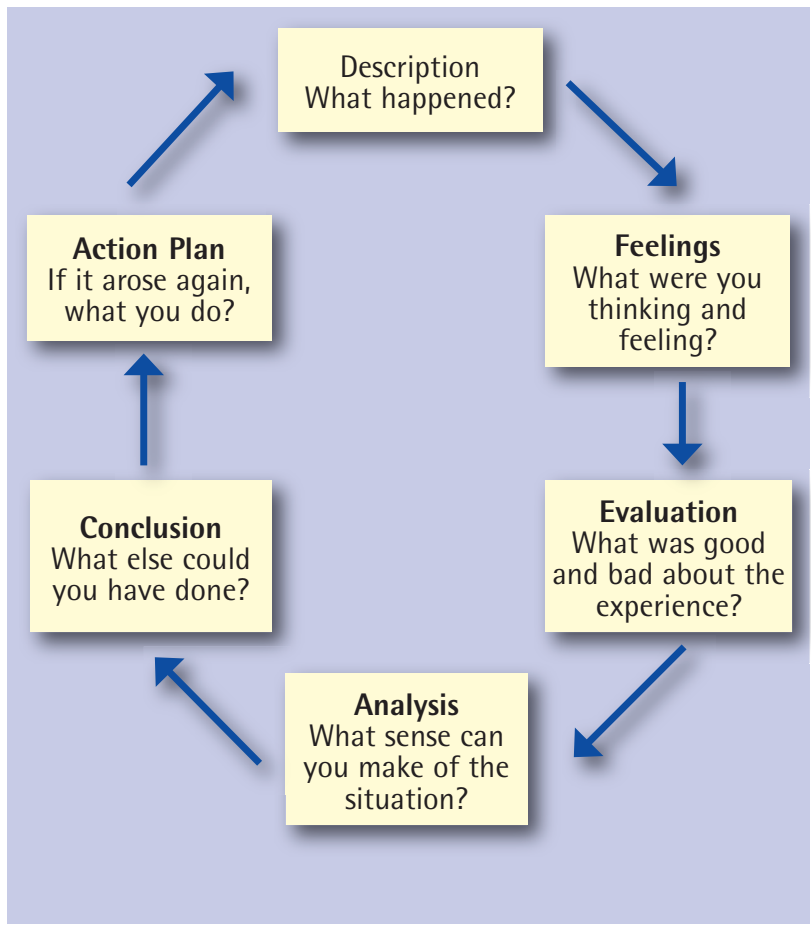

Figure 1. Gibbs's reflective cycle (1988) hydrocephalus management, as well as the psychological support of patients and families.

\section{Reflective practice}

Reflective practitioners value reflection and use theory and research findings to evaluate and decide best practice within the clinical environment (Johns, 1995). These skills are essential as advanced nurse practitioners must be able to assess and analyse what they are doing and critically reflect on their actions to improve patient outcomes. This challenging and complex role requires that advanced practice nurses adjust the boundaries for the development of future practice, pioneer and develop new roles responsive to changing needs, advance clinical practice, research and educate to enrich professional practice (Glaze, 2002).

\section{ABSTRACT}

Subarachnoid haemorrhage is a life-threatening event that presents with a number of discrete signs and symptoms making diagnosis problematic. A delay in diagnosis significantly increases morbidity and mortality and therefore places vulnerable patients at risk. Advanced nursing assessment and management is imperative to promote optimum patient outcomes and therefore decrease morbidity and mortality in acutely ill patients.

In this article a case study is discussed with reference to relevant literature to explore an evidence-based approach to the nurse's role, care and management of an acutely ill neuroscience patient with subarachnoid haemorrhage. In keeping with the reflective case study approach, Gibbs's reflective cycle (1988) and case study guidelines by Aitken and Marshall (2007) are used to identify areas of effective clinical practices and identify gaps in the literature. On the basis of this evaluation, suggestions for clinical improvements are made.

A reflective cycle can identify areas where clinical practice could be improved. It is hoped that this article will help nurses critically reflect on their own practice in the care and management of an acutely ill patient with subarachnoid haemorrhage.

\section{Key words}

Subarachnoid haemorrhage Nursing Management Reflective case study

Advanced practice Vasospasm Hydrocephalus Nimodipine

Accepted for publication following double blind peer review 6 October 2009. 


\section{Table 1. Glasgow Coma Scale}

Eye Opening
- Spontaneous
- To Voice
- To Pain
- None

Verbal Response

- Orientated

- Confused

- Inappropriate words

- Incomprehensible words

- None

\section{Score}

4

3

2

1

Motor Response

- Obeys Commands

- Localises to Pain

- Withdrawal to pain

- Flexion to pain abnormal

- Extension to pain

- None

\section{5}

4

3

2

1

From: Teasdale and Jennett, 1974.

Gibbs's reflective cycle is used in this study because it encourages nurses to provide a clear description of a particular event and through analysis and evaluation of feelings, helps to develop an action plan and conclusion that may be different as a result of the reflective process that has occurred (Gibbs 1988). It is important to observe that reflection does not always occur in the sequence of events in which Gibbs has used in the cycle. Reflection as represented in this case study jumps from one component to another to aid analysis, critical thinking and allow the practitioner to draw conclusions through reflection on relevant literature and nursing management.

\section{Descriptive history}

Mrs A is a 64-year-old lady who presented to a local hospital with a chief complaint of severe pain which was measured at 6/10 using a visual numerical scale (with 0 meaning 'no pain' and 10 meaning 'worst pain imaginable') (McCaffery and Pasero, 1999). Mrs A stated that she had 'never had a headache like this before'. The headache had had a 3-day gradual onset with no associated symptoms and paracetamol gave her mild relief. Mrs A could normally manage her duties at home, had no medical history, smoked half pack of cigarettes a day for 40 years and was allergic to sulphur.

Mrs A scored 15/15 on the GCS: she opened her eyes spontaneously, obeyed commands by 'poking out her tongue' and was oriented to time, place and person with a full Mental Status Quotient (MSQ), answering all 10 questions as per hospital policy (Teasdale and Jennett, 1974; Princess Alexandra Hospital, 2007) (Table 2). Mrs A was moving both upper and lower limbs spontaneously

\section{Table 2. Mental Status Quotient (MSO)}

\begin{tabular}{|c|c|}
\hline 1 & Where are you now? \\
\hline 2 & Which city is this? \\
\hline 3 & What is today's date? \\
\hline 4 & What month is it? \\
\hline 5 & What year is it? \\
\hline 6 & When is your birthday? \\
\hline 7 & What year were you born? \\
\hline 8 & How old are you? \\
\hline 9 & Who is the current Australian Prime Minister? \\
\hline 10 & Who was the previous Prime Minister? \\
\hline
\end{tabular}

with full and equal strength, and her pupils were equal and reactive to light at $3 \mathrm{~mm}$ in diameter. Her vital signs included a blood pressure of $138 / 69 \mathrm{mmHg}$, regular pulse rate of 83 beats/minute, a temperature of $37.3^{\circ} \mathrm{C}$, a regular respiratory rate of 20 breaths per minute and an oxygen saturation rate $\left(\mathrm{SO}_{2}\right)$ of $96 \%$ on room air.

A non-contrast computed tomography (CT) scan of the head was conducted and showed an $11 \times 13 \mathrm{~mm}$ nodule in the left posterior communicating artery, which was indicative of a large aneurysm. There was no evidence of subarachnoid or intraparenchymal blood. Mrs A was transferred to a specialized neurosurgical teaching hospital for further imaging and treatment.

\section{Feelings}

On reflecting on Mrs A's condition, the author felt that she was very fortunate and lucky to have presented to a hospital with CT imaging readily available over the weekend. If Mrs A's acute headache had occurred during the week and she had gone to general practice, lack of access to CT may have delayed treatment, particularly in the absence of symptoms commonly associated with subarachnoid haemorrhage such as nausea, vomiting, neck stiffness and photophobia (Wilson et al, 2005; Hickey, 2007). One in 20 people with subarachnoid haemmorrhage are missed on their first emergency department presentation and the risk is greater in patients with low acuity presentations (Vermeulen and Schull, 2007). Unrecognized subarachnoid haemorrhage is often diagnosed as 'migraine' or 'headache', delaying diagnosis and increasing the risk of mortality (Vermeulen and Schull, 2007).

Mrs A was haemodynamically stable, in good spirits but very nervous about the uncertainty of her condition and treatment. It is important to ensure that subarachnoid haemorrhage patients are kept calm, nursed in a quiet environment, and given adequate analgesia to decrease surges in blood pressure and the stress response. This approach helps minimize the risk of rebleeding (Wilson et al, 2005). 


\section{Computed tomography angiography}

Computed tomograpy angiograpy (CTA) is a non-invasive procedure that visualizes cerebral blood flow, abnormalities or obstructions but is thought to be only $90 \%$ accurate (Scanlon, 2004). CTA made a positive diagnosis of a left posterior communicating artery aneurysm, and Mrs A was moved to the high dependency unit on 2-hourly observations overnight to detect transient neurological changes. Mrs A was given analgesia for pain management, administered normal saline $125 \mathrm{ml} /$ hour intravenously and was made nil by mouth at 6 am for a high quality four-vessel cerebral digital subtraction angiogram (DSA) in the morning (Edlow et al, 2008).

\section{Cerebral digital subtraction angiogram}

A cerebral DSA is an invasive radiological procedure that allows precise visualization of all intracranial vessels and can clearly demonstrate any cerebrovascular abnormalities such as multiple aneurysms, arteriovenous malformations and cerebral vasospasm (Scanlon, 2004). Mrs A's cerebral DSA confirmed a left dominant oval shape posterior communicating artery aneurysm with a further small $2.5 \mathrm{~mm}$ anterior carotid artery aneurysm.

\section{Aneurysms}

An intracranial aneurysm, as defined by Wagner and Stenger (2005), is as an abnormal outpouching or dilation of an intracranial artery. Risk factors such as cigarette smoking, history of hypertension and the consumption of alcohol can increase the risk of rupture. Wagner and Stenger (2005) reported that females have a higher risk of rupture than males and patients who harbor multiple aneurysms are at higher risk of subarachnoid haemorrhage than those with a single aneurysm. Yasui et al (1997) found that the average annual rupture rate for a single aneurysm was $1.9 \%$ compared to $6.8 \%$ for multiple aneurysms. Wagner and Stenger (2005) also demonstrated that aneurysms that were more than $10 \mathrm{~mm}$ in diameter had rupture rates that were about twenty times higher than those of smaller aneurysms.

As a result of the evidence presented, Mrs A was at high risk of aneurysmal rupture: she is female, a smoker and had two aneurysms with the dominant one $>10 \mathrm{~mm}$ in diameter. Mrs A needed to be monitored closely by experienced neuroscience nurses to detect any transient neurological changes in her condition (Stevens and Moat 1996).

\section{Endovascular coiling}

Endovascular coiling provides a lower short-term risk alternative to surgery (Wagner and Stenger, 2005). A microcatheter is placed under radiographic guidance within the aneurysm and multiple platinum coils are inserted until a thrombus forms in the aneurysm (Kaptain et al, 2000; Wagner and Stenger, 2005). The only multicentre prospective randomized controlled trial comparing surgical clipping and endovascular coiling of ruptured aneurysm is the International Subarachnoid Aneurysm Trial (ISAT). This study of 2143 patients found that the relative risk of death or significant disability at 1 year for patients treated with coils was $22.6 \%$ lower than in surgically treated patients (Molyneux et al, 2002). Because of the size of the aneurysmal neck and the position of the aneurysm in the posterior circulation, Mrs A was suitable for coiling of her left posterior communicating artery aneurysm $(13 \times 10 \times 8 \mathrm{~mm})$. During the procedure, there was clear evidence of a left anterior cerebral artery aneurysm at $2.5 \mathrm{~mm}$, which was not treated immediately as the left posterior artery aneurysm was a higher priority owing to its size and risk of rupture.

\section{Nursing management}

On return to the high dependency unit, Mrs A was acutely confused and drowsy with a GCS 13 (E3 V4 M6) and answering one of the ten MSQ questions. Pupils were both sluggish and unequal with the left size 3 and right size 2, limb strength on both upper and lower limbs was $4 / 5$ on the muscle strength grading scale (Cauthorne-Burnette and Estes, 2006). Vital signs observations included a blood pressure of $177 / 64 \mathrm{mmHg}$, regular heart rate of 50 beats/ minute, respiratory rate $16-20$ breaths/minute, temperature $37^{\circ} \mathrm{C}$, and an oxygen saturation of $100 \%$ with 2 litres oxygen via nasal prongs, as minimal oxygen was required to achieve a good saturation level for brain perfusion.

Mrs A was commenced on appropriate analgesia for headaches and stool softeners for the prevention of constipation, as when patients perform the valsalva manoeuvre ICP increases (Keenan, 2006). A heparin infusion was commenced to prevent the formation of thrombo-emboli forming at the neck of the embolized aneurysm, thus preventing stroke, and intravenous sodium chloride $0.9 \%$ was given for adequate hydration (Stevens and Moat, 1996).

Mrs A had an indwelling urinary catheter draining $>100 \mathrm{ml} /$ hour of yellow-coloured urine to maintain adequate fluid balance. Neurovascular observations were performed according to protocol to detect neurovascular compromise and revealed good capillary return, $2+$ dorsalis pedis pulses, whitish/pink coloured toes at a warm temperature with normal sensation and no visible exudate or haematoma development on the right groin site.

Nursing care of patients who have undergone endovascular embolization includes checking skin integrity every 2 hours to prevent pressure areas, applying compression stockings for the prevention of deep vein thrombosis and pulmonary embolism, and keeping the patient supine with the affected leg in a straight position to facilitate healing of the puncture site and prevention of hematoma or bleeding at the angiography site (Keenan, 2006; Stevens and Moat, 1996; van Gijn et al, 2007).

\section{Subarachnoid haemorrhage}

A subarachnoid haemorrhage is any bleed underneath the arachnoid meninges of the brain and is most commonly related to a ruptured cerebral aneurysm (Scanlon, 2004). Subarachnoid haemorrhage can also occur as a result of trauma, stroke, and arteriovenous malformation, or an unidentifiable cause (Scanlon, 2004). 
Owing to Mrs A's poor neurological progress after the endovascular coiling procedure, the neurosurgical team ordered a postoperative CT head scan that confirmed subarachnoid haemorrhage, intraventricular haemorrhage, hydrocephalus and cerebral oedema (Table 3).

On evaluation, this outcome was very unfortunate, because it significantly worsened Mrs A's prognosis- $40 \%$ of patients die within 1 month of a subarachnoid haemorrhage, $30 \%$ of patients who survive the subarachnoid haemorrhage remain dependent, and of those who recover to an independent state, 50-70\% report a decrease in quality of life (Wilson et al, 2005). Detailed observation and a proactive response to Mrs A's signs and symptoms led to a quick diagnosis of the aneurysm and referral for the coiling procedure, but it was unfortunate that the second aneurysm could not be treated immediately.

\section{Nursing management of subarachnoid haemorrhage Neurological observations}

The GCS is a standardized tool for the assessment of neurological function and progress after trauma (Hickey, 2007). Close neurological observations in neurosciences critical care or high dependency is essential for prompt treatment and management of subarachnoid haemorrhage (Wijdicks et al, 2005). It is essential to enable nurses to make precise comparisons between the data collected at different times (Keenan, 2006). A fully conscious person is awake, alert and oriented to time, person, place and current circumstances, and although consciousness may be suddenly and completely lost, the decline is usually progressive (Copstead and Banasik, 2005). On return to the ward after the coiling procedure, Mrs A was severely confused and becoming increasingly drowsy. Cortical neurons are very sensitive, and cognitive and memory functions can be impaired early. Moreover, as the function of the reticular activating system becomes compromised the patient becomes more difficult to arouse (Copstead and Banasik 2005).

\section{Table 3. Mrs A's pathway}

1 Presented to hospital with severe headache: GCS 15/15

2 CTA indicated left posterior communicating artery (LPCA) aneurysm

3 Transferred to HDU for DSA which confirmed diagnosis

4 Underwent endovascular coiling for LPCA. A left anterior cerebral artery aneurysm was observed but could not be treated immediately

5 Returned to HDU: GCS 13/15 and MSO 1/10

6 Postoperative CT showed subarachnoid aneurysm, intraventricular haemorrhage, hydrocephalus, cerebral oedema

$\mathrm{CTA}=$ computed tomography angiogram; DSA = cerebral digital subtraction aneurysm; GCS = Glasgow Coma Scale; HDU = highdepenency unit; MSQ = Mental Status Quotient
A change in level of consciousness is one of the most sensitive indicators of altered brain function therefore meticulous monitoring of warning signs that could contribute to early detection of secondary insults is of great importance in the management of a subarachnoid haemorrhage patient (Copstead and Banasik, 2005; Hedlund et al, 2008). Hedlund et al (2008) also report that monitoring of vital physiological parameters to draw correct and prompt conclusions from collected data to alert physicians is essential nursing care and this was conducted effectively in the high dependency unit.

\section{Blood pressure}

Hypertension is common following subarachnoid haemorrhage. Activation of the sympathetic nervous system provides a compensatory mechanism to maintain adequate cerebral blood flow in the presence of impaired autoregulation (Copstead and Banasik, 2005; Wilson et al, 2005). Autoregulation is pressure controlled to maintain adequate cerebral blood flow, taking into account ICP values and mean arterial pressure (MAP) (Cook, 2004). Cerebral perfusion pressure (CPP) is the pressure required to maintain cerebral blood flow and is measured by subtracting the ICP from the MAP (CPP=MAP-ICP) (Sheppard and Wright, 2006). In general, the MAP should not fall below about $70 \mathrm{mmHg}$ and a MAP between 105-120 mmHg is recommended for subarachnoid haemorrhage patients to maintain intravascular volume and minimize delayed ischemic deficit (Copstead and Banasik, 2005; Ohkuma et al, 2000). It is reported that blood pressure should be kept in the 'high normal' range for a secured subarachnoid haemorrhage patient in an attempt to maintain CPP and improve patient outcomes (Wilson et al, 2005).

Patients with aneurysmal subarachnoid haemorrhage have shown improved outcomes with the reduction of vasospasm when on calcium antagonists such as nimodipine, with an absolute risk reduction of $5.1 \%$ according to a Cochrane review (Rinkel et al, 2005). Hypotension as a possible side effect of nimodipine needs to be recognized and treated early and this may be achieved easier if patients are on a nimodipine infusion that can be titrated according to blood pressure parameters. Hypotension is poorly tolerated in subarachnoid haemorrhage patients and must be promptly detected by nurses and managed to prevent further brain ischaemia (Copstead and Banasik, 2005).

In Mrs A's case, systolic blood pressure was maintained at $130-160 \mathrm{mmHg}$ as ordered and documented by the medical team. MAP, however, may be a more appropriate clinical measurement of brain haemodynamics than systolic blood pressure alone, and if patients are monitored for ICP, CPP is easily calculated to determine adequate cerebral blood flow. On analysis and critical reflection, documentation of MAP parameters instead of systolic blood pressure may need to be changed in current practice to accurately manage brain haemodynamics in subarachnoid haemorrhage patients. 


\section{Cushing's triad}

Neuroscience nurses need to monitor for Cushing's triad which is observed in acute ICP and presents with three signs (Crimlisk and Grande, 2004):

- Increasing systolic blood pressure with widening pulse pressure

- Bradycardia

Irregular breathing patterns.

These three manifestations are late signs of increased ICP and indicate that the brain is about to herniated (Lower, 2002). Biot's breathing, which is irregular breathing with apnoeic episode may be seen in raised ICP (Crimlisk and Grande 2004). Nurses are required to describe the breathing pattern as it is seen and assess for specific changes vigilantly.

When Mrs A returned after the coiling procedure she had signs of raised ICP with a pulse rate of 50 beats/ minute and temporarily developed a widening pulse pressure and increased systolic blood pressure which was resolved. On reflection, her respiratory rate was between 16-20 breaths/minute with no evidence of respiratory rhythm or pattern in the medical notes. Control centres for blood pressure, heart rate and respiration are all located within the brainstem and these vital signs are therefore an indication of brainstem function (Shah, 1999). There is evidence that nursing staff may be reluctant or resistant to correctly assessing and documenting patients' respiratory rate (Considine, 2005; Cretikos et al, 2008). Yet, this important vital sign remains the most sensitive indicator of an adverse event. This is an important sign of Cushing's triad and therefore an indication of raised ICP.

\section{Pupillary assessment}

Pupillary assessment needs to be recorded individually. It provides important information about the function of the brainstem and cranial nerves II (optic) and III (oculomotor) (Copstead and Banasik, 2005; Sheppard and Wright, 2006). Careful nursing monitoring of pupillary response to light in acute neurosurgical patients is critical, as failing response may be the first indication of brain compression (Copstead and Banasik 2005). On analysis of the case study, Mrs A acutely developed sluggish, unequal pupils which evidence suggests is ominous and results from pressure on the oculomotor nerve by lateral displacement of midbrain structures (Copstead and Banasik, 2005). This displacement was evident owing to her subarachnoid haemorrhage and intracranial haemorrhage after the coiling procedure.

On reflection on the interventions given, nurses intervened early and medical staff were informed of the changes promptly as a result of strict postoperative observations according to organizational policy and procedures. Notification of early neurological changes prompts for early interventions and can improve patient outcomes.

\section{Fluid management}

Nurses need considerable knowledge in how to manage fluid and hydration in patients suffering from subarach- noid haemorrhage (Hedlund et al, 2008). Early research indicates that patients with a daily fluid intake of a least 3 litres, withholding of any antihypertensive medications, reduces mortality alone by $10 \%$ (Cook 2004; Weir and MacDonald, 1993). While no human randomized trials have been undertaken to validate 'triple-H therapy' (hypervolaemia, hypertension and haemodilution), as difficult to blind with complicated ethical issues, strong evidence exists that such interventions can reverse delayed ischaemic deficit through restoration of cerebral blood flow (Cook, 2004; van Gijn et al, 2007; Wilson et al, 2005). Wilson et al (2005) reported that non-randomized controlled trials in which patients were given at least 3 litres per day of saline $0.9 \%$ have indicated a decreased rate of delayed cerebral ischaemia and a better overall outcome.

If vasospasm is confirmed or suspected in the presence of neurological deterioration, triple- $\mathrm{H}$ therapy may be instituted (Wood and Nowitzke, 2005). Wilson et al (2005) reported that triple-H therapy is only initiated after definitive treatment of the aneurysm because of an increased risk of rupture. Mrs A had $0.9 \%$ normal saline running $125 \mathrm{ml} /$ hour, nimodipine $10 \mathrm{ml} /$ hour with coinfusion $0.9 \%$ normal saline at $40 \mathrm{ml} /$ hour, giving a total of $175 \mathrm{ml} /$ hour.

When systolic blood pressure dropped below $120 \mathrm{mmHg}$, Gelofusion was given to improve intravascular volume. Tseng et al (2008) outlined the uncertainty about the best choice of fluids owing to a lack of well-powered randomized controlled trials. One randomized controlled trial had larger doses of synthetic colloid fluids, which was correlated with increased haemodilution, elevated systemic inflammation and reduced strength of cerebral autoregulation on the ipsilateral side of the ruptured aneurysm, where a maximal subarachnoid haemorrhageinduced inflammation is most likely to occur (Tseng et al, 2008). Therefore intravenous fluid therapy using synthetic colloids or blood transfusions may be associated with increased unfavourable outcome following subarachnoid haemorrhage (Tseng et al, 2008).

Critical analysis of this study shows two closely scrutinized randomized controlled trials although the weakness is its nonrandomized nature and the relatively small sample size, which limits the validity of any subgroup analysis. Nurse practitioners must be open to critiquing the literature, and to evaluating and challenging practices with reference to research, including being prepared to make changes in practice to improve patient outcomes.

\section{Vasospasm}

Cerebral vasospasm typically develops several days after the initial subarachnoid haemorrhage, peaking 7-10 days after and lasting up to 2 weeks (Wood and Nowitzke, 2005). Vasospasm is described as a prolonged period of constriction of blood vessels in response to irritants in the subarachnoid space (Cook, 2004). Cook (2004) highlighted the main consequences of vasospasm as:

Delayed ischaemic deficit

Altered cerebral blood flow 


\section{Decreased CPP.}

Thirty per cent of patients with vasospasm die, 34\% have permanent deficits, and the remainder make a good recovery with appropriate treatment (Cook, 2004).

\section{Hydrocephalus}

Patients are at risk of developing acute hydrocephalus or intraventricular blood after subarachnoid haemorrhage and neuroscience nurses need to monitor and assess signs of these (van Gijn et al, 2007). Patients with acute hydrocephalus often present with a reduced level of consciousness, headache with associated nausea and vomiting, and gait or walking difficulties (Keenan, 2006). If a patient becomes drowsy, is haemodynamically stable and has evidence of dilated ventricles (hydrocephalus), a policy of wait and see for 24 hours by the medical team is justified because spontaneous improvement can be expected in about half of patients (van Gijn et al, 2007).

Four days after the coiling and bleed, Mrs A suddenly dropped her GCS to 10, opening eyes to speech, obeying commands, but unable to give a verbal response, resulting in global aphasia. CT head results and angiogram with vasodilating agent verapamil intra-arterially confirmed vasospasm and acute hydrocephalus. An external ventricular drain was inserted in the lateral ventricle allowing cerebral spinal fluid (CSF) to flow into a closed external system for measurement and close nursing management and assessment of CSF colour, clarity and volume (Hickey, 2007). After surgery, Mrs A went to the intensive care unit for strict arterial blood pressure monitoring and inotrope support for the management of vasospasm (Smith, 2007).

On reflection and analysis of this case study it was noted that Mrs A had been awaiting an intravenous re-site for 4 hours. Although nursing staff monitored and maintained systolic blood pressure above $130 \mathrm{mmHg}$, the decreased intravascular volume and cerebral perfusion may have resulted in the development of vasospasm. This demonstrates that, although these patients appear to be improving, they remain at significant risk of acute life-threatening deterioration, and effective, timely and appropriate nursing assessment and observation is imperative.

\section{Psychological support}

Nurses are faced with and have both the worries and thoughts of relatives with different types of questions on the long-term outlook, with respect to psychic and physical disability (Hedlund et al. 2008). In a study nurses viewed providing support to patients with subarachnoid haemorrhage as a process ranging from highly advanced technological care to 'softer' more emotional care (Hedlund et al. 2008).

There have been reports of increased vulnerability to developing depression after subarachnoid haemorrhage (Hedlund et al, 2008). This highlights the importance of nurses being able to distinguish between sadness and depression and why an interdisciplinary approach is essential to offer the patient and family the best care after trauma. Social workers, occupational therapists and physiotherapists are needed to provide ongoing emotional, cognitive and physical support to effectively treat and manage neurosurgical patients with impairments due to cerebral insult. It is important for nurses to provide ongoing consistent and repetitive information to the patient and family about possible complications after subarachnoid haemorrhage and prevention techniques to better prepare them for the onset of cerebral vasospasm which can occur up to 21 days after the initial bleed (Twedell, 2004). In a qualitative study of the views of 18 nurses (17 female and 1 male), changes in cognition and perception such as memory loss, concentration difficulties, hallucinations and loss of insight were regareded as obstacles in aneurysmal subarachnoid haemorrhage patients (Hedlund et al, 2008).

Mrs A and her family went through times of sadness, hopelessness and disappointment after the complications of the subarachnoid haemorrhage, and Mrs A's lack of insight, confusion and memory loss proved stressful for the family.

Mrs A spent 57 days in hospital after further complications during her stay, including infection, falls and the insertion of a ventricular peritoneal shunt. Her determination to get home with the help of physiotherapists and occupational therapists proved successful and she was able to be discharged home on 24 hour supervision with the appropriate follow-up including physiotherapy, neuropsychiatry and neurosurgical outpatient appointments.

\section{Discussion}

A reflective framework and case study approach can identify key discussion points and recommendations for changes in practice as well as make a meaningful contribution to the literature (Gibbs, 1988; Aitken and Marshall, 2007) (Table 4). On reflection, the MSQ tool used in the author's health-care setting may not be the most appropriate and valid assessment for nurses to use for assessment of orientation. According to the research, for a patient to be fully orientated he/she must be able to tell the assessor who he/she is, where he/she is, what day it is (day, month and year), and why he/she is where in he/she is (Teasdale and Jennett, 1974; Shah, 1999). Asking a patient 'what is today's date?' has been argued as an invalid question as everyone may not know the date on a daily basis. Orientation to person, place and time is sufficient (Lower, 2002).

The orientation assessment of the GCS looks at a higher function controlled by the reticular activating system in the brainstem (Lower, 2002; Hickey, 2007). Orientation has four components of awareness including orientation, memory (short and long term), calculation and fund of knowledge (current prime minister) (Lower 2002). The MSQ achieves all these requirements except for calculation, which could be addressed with the inclusion of an additional test. Consistency is the key when educating nursing staff and assessing neurological function. A set of 


\section{Table 4. Action plan}

Investigate the currently used MSO tool: find out what other facilities use, and consider the need to modify the MSO to accurately assess orientation in neuroscience patients

Affirm the need for accurate documentation of respiratory rate and rhythm to assess brainstem function with nursing staff when assessing neuroscience patients

Highlight the point that mean arterial pressure is a more accurate measurement of brain haemodynamics than systolic blood pressure alone when managing the fluid status of subarachnoid haemorrhage patients

Improvements in nursing competency for peripheral intravenous cannulation will decrease the risk of compromised patient care for subarachnoid haemorrhage patients owing to medical workload demand or inefficiency

Education for nursing staff in the value of case study analysis and reflective practice will encourage critical thinking and changes in clinical practice to improve patient outcomes

key questions to assess orientation that may need to be modified according to the research is important to identify transient changes that lead to confusion and neurological deficit.

Mrs A did not have an intra venous cannula sited when she required one. On reflection this may have contributed to a lower intravascular volume and therefore the development of vasospasm. Subarachnoid haemorrhage patients who have at least 3 litres of fluid per day have a decreased the rate of delayed cerebral ischaemia with a better overall outcome (Cook, 2004; Wilson et al, 2005). Although Mrs A obtained an overall fluid intake above 3 litres, it is best to prevent a delay occurring so patients receive the best patient care. On reflection, this could be rectified through increased awareness for staff to obtain competence in peripheral intravenous cannulation so that when doctors are busy with other patients and medical emergencies, patient care is not compromised. Increased nursing competence in peripheral intravenous cannulation will allow nurses to actively respond to acute neurosurgical patients and this may decrease the potential for complications after subarachnoid haemorrhage.

\section{Conclusions}

Caring for a neurosurgical patient involves intense nursing care in an acute neurosurgical unit to achieve the best possible outcome after subarachnoid haemorrhage. Nurses require an in-depth understanding of the mechanisms, which underpin the physiology of subarachnoid haemorrhage in order to provide appropriate nursing care based on the evidence (Cook, 2004). This reflective case study demonstrates to nurses the value of reflective practice in critically analysing the literature and questioning clinical practices to improve patient outcomes using Gibbs's (1988) reflective cycle and Aitken and Marshall's (2007) case study guidelines. Advanced nurse practitioners are required to use and critique the literature, and with further education, nurses will understand the acute role they play in the management of postoperative coiling, subarachnoid patients and the intense monitoring for signs of cerebral insult using basic neurological assessment skills.

The reflection discussed in this article has identified areas of practice that need to be investigated. As a result an action plan has been developed to improve nursing practice. It is hoped that the application of this approach will improve patients' morbidity and mortality after subarachnoid haemorrhage and lead to better outcomes in the future.

BJNN

Acknowledgment: The author would like to acknowledge Debbie Massey, lecturer, Griffith University, for her continual support and encouragement throughout her postgraduate studies.

Conflict of interest: none declared

Aitken LM, Marshall AP (2007) Writing a case study: Ensuring a meaningful contribution to the literature. Aust Crit Care 20(4): 132-6 Cauthorne-Burnette T, Zator Estes ME (2006) Clinical Companion to Accompany Health Assessment and Physical Examination 3rd edn. Thomson/Delmar Learning, Clinton Park, New York

Considine J (2005) The role of nurses in preventing adverse events related to respiratory dysfunction: literature review. $J A d v$ Nurs 49(6): 624-33

Cook NF (2004) Subarachnoid haemorrhage and vasospasm: using physiological theory to generate nursing interventions. Intensive Crit Care Nurs 20(3): 163-73

Copstead LE, Banasik JL (2005) Pathophysiology 3rd edn. Elsevier Saunders, St Louis, MO

Cretikos MA, Bellomo R, Hillman K, Chen J, Finfer S, Flabouris A (2008) Respiratory rate: the neglected vital sign. Med J Aust 188(11): 657-9

Crimlisk JT, Grande MM (2004) Neurologic assessment skills for the acute medical surgical nurse. Orthop Nurs 23(1): 3-9; quiz 10-11

Edlow JA (2007) Diagnosis of subarachnoid hemorrhage: are we doing better? Stroke 38(4): 1129-31

Edlow JA, Malek AM, Ogilvy CS (2008) Aneurysmal subarachnoid hemorrhage: update for emergency physicians. J Emerg Med 34(3): 237-51

\section{KEY POINTS}

Morbidity and mortality as a result of subarachnoid haemorrhage remain high, and signs and symptoms can be easily misdiagnosed resulting in delayed treatment

Accurate assessment and documentation of vital signs including respiratory rhythm is essential in detecting early complications after subarachnoid haemorrhage

Reflective practice and critical analysis of current literature is vital to improve clinical practice and patient outcomes

Strict fluid management and continual intravascular volume support is critical in subarachnoid haemorrhage patients for the prevention of vasospasm

Psychological support from an interdisciplinary team is essential to effectively manage patients and families after subarachnoid haemorrhage 
Gibbs G (1988) Learning by Doing: A Guide to Teaching and Learning Methods. Oxford Polytechnic, Oxford

Glaze JE (2002) Stages in coming to terms with reflection: student advanced nurse practitioners' perceptions of their reflective journeys. $J$ Adv Nurs 37(3): 265-72

Hedlund M, Ronne-Engstrom E, Ekselius L, Carlsson M (2008) From monitoring physiological functions to using psychological strategies. Nurses' view of caring for the aneurysmal subarachnoid haemorrhage patient. J Clin Nurs 17(3): 403-11

Hickey J (2007) The Clinical Practice of Neurological and Neurosurgical Nursing. 5th edn. Lippincott Williams, Philadelphia Johns C (1995) Achieving Effective Work as a Professional Activity. Gray Publishing, Tunbridge Wells

Kaptain GJ, Lanzino G, Kassell NF (2000) Subarachnoid haemorrhage: epidemiology, risk factors, and treatment options. Drugs Aging 17(3): 183-99

Keenan G (2006) Arteriovenous Malformation: A Paediatric Case Study. Australasian Journal of Neuroscience 17(2): 13-22

Lower J (2002) Facing neuro assessment fearlessly. Nursing 32(2): 5864; quiz 65

McCaffery M, Pasero C (1999) Pain: Clinical Manual 2nd edn. Mosby, St Louis

Molyneux A, Kerr R, Stratton I, Sandercock P, Clarke M, Shrimpton J, Holman R (2002) International Subarachnoid Aneurysm Trial (ISAT) of neurosurgical clipping versus endovascular coiling in 2143 patients with ruptured intracranial aneurysms: a randomised trial. Lancet 360(9342): 1267-74

Ohkuma H, Manabe H, Tanaka M, Suzuki S (2000) Impact of cerebral microcirculatory changes on cerebral blood flow during cerebral vasospasm after aneurysmal subarachnoid hemorrhage. Stroke 31(7): $1621-7$

Princess Alexandra Hospital (2007) Mental Status Quotient (MSQ). Princess Alexandra Hospital, Woolloongabba, Queensland, Australia

Rinkel GJ, Feigin VL, Algra A, van den BerghWM, Vermeulen M, van Gijn J (2005) Calcium antagonists for aneurysmal subarachnoid haemorrhage. Cochrane Database Syst Rev 2005(1): CD000277

Scanlon A (2004) Aneurysmal subarachnoid haemorrhage--part 1: Preoperative nursing management diagnosis, complications and treatment: a composite case study. Contemp Nurse 17(1-2): 80-8

Shah S (1999) Neurological assessment. Nurs Stand 13(22): 49-56

Sheppard M, Wright M (2006) Principles and Practice of High Dependency Nursing 2nd edn. Elsevier, Edinburgh

Smith M (2007) Intensive care management of patients with subarachnoid haemorrhage. Curr Opin Anaesthesiol 20(5): 400-7

Stevens F, Moat J (1996) Innovative changes in the management of aneurysms. Australasian Journal of Neuroscience 9(3): 16-20

Teasdale G, Jennett B (1974) Assessment of coma and impaired consciousness: A practical scale. Lancet 2(7872): 81-4

Thelan L Urden L, Lough M, Stacy K (1998) Critical Care Nursing: Diagnosis and Management 3rd edn. Mosby, St Lousi

Tseng MY, Hutchinson PJ, Kirkpatrick PJ (2008) Effects of fluid therapy following aneurysmal subarachnoid haemorrhage: a prospective clinical study. Br J Neurosurg 22(2): 257-68

Twedell D (2004) Aneurysmal Subarachnoid Hemorrhage. The Journal of Continuing Education in Nursing 35(4): 150

van Gijn J, Kerr RS, Rinkel GJ (2007) Subarachnoid haemorrhage. Lancet 369(9558): 306-18

Vermeulen MJ, Schull MJ (2007) Missed diagnosis of subarachnoid hemorrhage in the emergency department. Stroke 38(4): 1216-21

Wagner M, Stenger K (2005) Unruptured intracranial aneurysms: using evidence and outcomes to guide patient teaching. Crit Care Nurs $Q$ 28(4): 341-54

Weir B, MacDonald L (1993) Cerebral vasospasm. Clin Neurosurg 40: 40-55

Wijdicks EF, Kallmes DF, Manno EM, Fulgham JR, Piepgras DG (2005) Subarachnoid hemorrhage: neurointensive care and aneurysm repair. Mayo Clin Proc 80(4): 550-9

Wilson SR, Hirsch NP, Appleby I (2005) Management of subarachnoid haemorrhage in a non-neurosurgical centre. Anaesthesia 60(5): 470 85

Wood MJ, Nowitzke AM (2005) Epidemiological aspects of spontaneous subarachnoid haemorrhage in Queensland, Australia. $J$ Clin Neurosci 12(7): 770-4

Yasui N, Suzuki A, Nishimura H, Suzuki K, Abe T (1997) Long-term follow-up study of unruptured intracranial aneurysms. Neurosurgery 40(6): 1155-9; discussion 1159-60

\section{CORRESPONDENCE}

\section{October diary: The family perspective}

\section{Dear Diary}

I am the Yorkshire Regional Co-ordinator for Headwaythe brain injury association, and the mother of a brain injured son. For the last 3 years I have been delighted to accept the invitation to present 'The Family Perspective' to the Neurology Nursing Students at the Royal Hallamshire Hospital, the Regional Unit in Sheffield.

This year I was asked to present my piece in the second slot of the day instead of the last, which reflects the growing awareness of the needs of families and the value of good communication.
My presentation consists of an overview of our own experience of service provision coupled with case studies gleaned over the last 10 years of working throughout Yorkshire. Issues covered in my presentation include:

Quality information

- Early family/peer support

Delivering bad news

- Differing professional opinions

Need for clarity of information delivered by named nurse

- Transparent consultation from the beginning

- Need for specialist services Ongoing support from acute-to-community with re-access at times of crisis.

Unless families are welcomed, included and enabled by education to come to terms appropriately with the situation, there is likely to be confrontation.

Conflicting opinions only serve to confuse the already exhausted and traumatized family and this wastes valuable nursing time.

As the leading charity offering support for those affected by brain injury, Headway is well placed to work with nursing staff to offer quality support

For more information please contact myself or Mandy Hassall, visit the Headway website, or call the dedicated helpline (Further information).

\section{Ann Hurley \\ Yorkshire Regional Co-ordinator, Headway}

email: yorkshire.regional.coordinator@headway.org.uk

Further information

Headway

www.headway.org.uk

Email services.director@

headway.org.uk

Helpline: 08088002244 
Copyright of British Journal of Neuroscience Nursing is the property of Mark Allen Publishing Ltd and its content may not be copied or emailed to multiple sites or posted to a listserv without the copyright holder's express written permission. However, users may print, download, or email articles for individual use. 